\title{
Diferenciação e envelhecimento do músculo do vôo em operárias de Scaptotrigona postica Latreille (Hymenoptera, Apidae)
}

\author{
Camila Marques Adade \& Carminda Cruz-Landim
}

Departamento de Biologia, Instituto de Biociências de Rio Claro, Universidade Estadual Paulista. 13506-900 Rio Claro, São

Paulo, Brasil.

\begin{abstract}
Differentiation and aging of the flight muscle in Scaptotrigona postica Latreille (Hymenoptera, Apidae) workers. The present paper deals with the differences verified in the flight muscle development of $S$. postica Latreille, 1807, a Brazilian stingless bee. As an advanced eusocial species, the workers of this bee have complex behavioral adaptations that turn them able to performe all tasks necessary to colony maintenance, among them the foragement. This last work requires a well functioning flight musculature. Measurements of the fiber diameters in histological slides and ultrastructural studies, showed differences in the fiber size and morphology related to the worker age and function in the colony. The ultrastructural features, also showed modifications in the fibers mitochondria, miofilaments, nuclei and amount of glycogen stored, as the worker ages or change functions.
\end{abstract}

KEY WORDS. Anatomy, histology, labor division, morphometry, muscle fiber, ultrastructure.

RESUMO. O presente artigo relata diferenças verificadas no desenvolvimento da musculatura do voo de S.postica Latreille, 1807, uma abelha sem ferrão nativa no Brasil. Tratando-se de uma espécie eussocial avançada, as operárias desta abelha apresentam complexas adaptações comportmentais que as habilitam a realizar as tarefas necessárias à manutenção da colônia, entre elas o forrageamento. Esta última tarefa requer uma musculatura do vôo funcional. Mensurações dos diâmetros e estudos ultra-estruturais das fibras musculares, mostraram diferenças morfológicas e de tamanho relacionadas à idade e função das operárias na colônia. A ultra-estrutura mostrou modificação na apresentação das mitocondrias, miofilamentos, núcleos e quantidade de glicogênio armazenado das fibras musculares, conforme a operárias envelhece ou muda de função.

PALAVRAS CHAVE. Anatomia, histologia, divisão de trabalho, morfometria, fibra muscular, ultra-estrutura.

Os músculos do vôo dos insetos estão dispostos em um par de feixes dorso-ventrais e um par antero-posterior localizados ambos no tórax. Estes músculos são designados músculos indiretos do vôo porque não se prendem às asas, mas ao exoesqueleto do tórax. A sua contração produz deformações na altura e largura do tórax, as quais resultam no movimento das asas cuja articulação se faz com o tórax. Os músculos dorso-ventrais elevam as asas enquanto os longitudinais flexionam-nas para baixo (SNODGRASS 1956, Wigglesworth 1974, Chapman 1998). Em Apis mellifera Linnaeus, 1758, os feixes dorso-ventrais estão presos dorsalmente ao tegumento e ventralmente a um apódema, enquanto que, os ântero-posteriores, estão presos às superfícies submediana posterior do primeiro fragma e submediana do mesoescutelo e à superfície anterior do segundo fragma torácicos (DALY 1969).

O músculo do vôo dos insetos é um músculo estriado similar em muitos aspectos ao músculo esquelético dos vertebrados, principalmente nos tipos de estruturas constituintes, diferindo principalmente no arranjo e disposição dessas estruturas, bem como no caminho pelo qual a tensão é transmitida para o exoesqueleto nos insetos. As miofibrilas das fibras musculares estão conectadas individualmente à cutícula do tegumento, ou à apódemas cuticulares formados pela invaginação da cutícula, através da ligação com tonifibrilas modificadas presentes nas células epidérmicas, os quais substituem o tendão de colágeno dos vertebrados. (SмyтH 1985). O contato entre as células epidérmicas e as musculares é reforçada por desmossomas e interdigitações das membranas aumentando a área de adesão em aproximadamente dez vezes (CrUZ-Landim 1970).

Nas abelhas, o músculo do vôo é assincrônico porque não se contrai em sincronia com a chegada dos impulsos nervosos (SNODGRASs 1956). Entretanto, os impulsos nervosos são necessários para o início do vôo e para a manutenção da contínua atividade do mesmo (Pringle 1949). A contração muscular deforma o tórax e devido ao pequeno encurtamento das fibras, a contração muscular pode ocorrer rapidamente (Pringle 1957).

As fibras musculares esqueléticas dos insetos podem ter seu diâmetro variando de poucos micrômetros a mais de $1 \mu \mathrm{m}$, são multinucleadas e o fato da área da superfície das fibras ser grande facilita a troca de metabólitos com hemolinfa (SMYTH 1985).

Revista Brasileira de Zoologia 21 (2): 379-384, junho 2004 
Os músculos do vôo em Scaptotrigona postica Latreille, 1807 (Apidae, Meliponinae) como nos outros insetos holometábolos, desenvolvem-se durante a pupação. No inseto adulto, estes músculos ocupam quase todo o tórax, são constituídos por fibras gigantes do tipo fibrilar, as maiores células musculares encontradas nos insetos medindo entre 150 e 300 $\mu \mathrm{m}$ de diâmetro. As fibras são multinucleadas, constituídas de numerosas miofibrilas, dispostas paralelamente e intercaladas com mitocôndrias muito grandes e vastamente areadas por ramos dos troncos torácicos de traquéias, sendo que as traqueolas mais delicadas penetram por invaginações da membrana da fibra muscular (Cruz-Landim \& GiometTi 1990).

A ultra-estrutura do músculo dos insetos, como em outros músculos estriados, mostra uma organização regular dos miofilamentos nas miofibrilas, e destas na fibra de maneira que determinam a sua subdivisão longitudinal em uma sucessão de sarcômeros e definem o padrão de estriação (PRINGLE 1965, SмITH 1984). Neste tipo de músculo a banda I é muito curta medindo $2 \mu \mathrm{m}$, enquanto a banda A mede $8 \mu \mathrm{m}$, disso resulta o pequeno encurtamento da fibra na contração, conforme observado por PRINGLe (1957).

As operárias de $S$. postica, desde sua emergência até aproximadamente 30 dias de vida adulta e dependendo das necessidades da colônia, realizam tarefas no interior do ninho (SIMÕES \& BEgo 1979). Logo depois à emergência, as operárias cuidam da limpeza própria e do ninho e ao redor do sexto dia passam a construir os favos para postura dos ovos pela rainha e a aprovisioná-los com alimento, sendo designadas nutridoras. Somente as operárias mais velhas (30-60 dias) passam a realizar tarefas fora do ninho, principalmente o forrageio, sendo então designadas campeiras. Portanto, apenas estas últimas operárias, que voam para fora do ninho, utilizam extensivamente sua musculatura. Estas tarefas são executadas pelas operárias em uma seqüência cronológica determinada por seu amadurecimento fisiológico e regulada pelas necessidades da colônia.

Tendo em vista o que este tipo de polifenismo exige da musculatura do vôo das operárias, o objetivo do presente artigo é verificar se ocorrem mudanças estruturais correspondentes nas fibras musculares que a constituem.

\section{MATERIAL E MÉTODOS}

\section{Material}

Foram utilizadas para este estudo, operárias recém-emergidas, nutridoras e campeiras de Scaptotrigona postica, que foram coletadas em colônias mantidas no Instituto de Biociências, Universidade Estadual Paulista, Campus de Rio Claro.

\section{Histologia}

O músculo do vôo das operárias executando as tarefas citadas acima foi coletado, dissecado e fixado em mistura de Dubosq-Brasil (Bouin alcoólico) para microscopia óptica. Desidratado, o material foi embebido em historesina Leica e incluído na mesma resina acrescida do seu catalisador. Os cortes com $5 \mu \mathrm{m}$ de espessura, foram corados com hematoxilina e eosina, montados em lâminas permanentes segundo procedimento usual, analisados e fotografados.

\section{Morfometria}

$\mathrm{O}$ diâmetro das fibras musculares foi medido em cortes histológicos transversais das fibras musculares do músculo dorso ventral, com o auxílio do Programa Manager-IMPACT (Graphic Applications) acoplado a um microscópio óptico Axioskop (Zeiss) provido de um sistema Axiohome. Os resultados foram submetidos ao teste estatístico de "Tukey" para comparação das médias.

\section{Microscopia Eletrônica de Transmissão (MET)}

Os músculos do vôo, dissecados, foram fixados em mistura de glutaraldeído a $2 \%$ com paraformaldeído a $4 \%$ em tampão cacodilato de sódio $0,1 \mathrm{M}(\mathrm{pH} 7,4)$ por seis horas. Em seguida foram lavados duas vezes com o tampão por 15 minutos cada e pós-fixados em solução de tetróxido de ósmio a 0,5\% contendo $0,8 \%$ de ferricianeto de potássio em tampão cacodilato de sódio $0,1 \mathrm{M}(\mathrm{pH} \mathrm{7,4)}$ por uma hora. Posteriormente, foram lavados duas vezes com o mesmo tampão por 15 minutos cada e deixados em solução de ácido tânico $0,15 \%$ por três horas.

Foi utilizada solução de acetato de uranila a 1\% em álcool a $10 \%$ por seis horas para contrastação do músculo, antes da desidratação que foi feita numa série de concentração crescente de acetona (70\%, 80\%, 90\%, 95\%, cinco minutos cada e 100 três vezes de cinco minutos). O material foi infiltrado em concentrações diferentes da resina Epon Araldite em acetona a $4^{\circ} \mathrm{C}$ por um total de duas horas e mais uma hora na resina pura. A seguir, as peças foram embebidas na resina acrescida do catalisador, por no mínimo cinco horas, incluídas na mesma resina e polimerizadas em estufa a $60^{\circ} \mathrm{C}$ durante 24 horas.

Os cortes foram contrastados com acetato de uranila e citrato de chumbo e posteriormente analisados em microscópio eletrônico de transmissão.

\section{Microscopia eletrônica de varredura}

Os músculos dissecados foram fixados em Karnovisky, desidratados, secados no ponto crítico, cobertos com filme de ouro, examinados e fotografados em microscópio eletrônico de varredura.

\section{RESULTADOS}

\section{Morfometria}

Nos insetos não existe uma membrana envoltória do tipo perimísio em torno dos feixes musculares, assim como não há tecido conjuntivo separando uma fibra da outra. As fibras são mantidas juntas por ramos traqueais (Fig. 1). A fibra muscular tem o sarcoplasma preenchido por numerosas miofibrilas (Figs 2 e 4) que no exame histológico aparecem intercaladas com núcleos, distribuídos na periferia e no interior da fibra, aparentemente ao acaso (Fig. 3). Devido à compactação de uma fibra contra a outra, estas apesar de tenderem a apresentar secção circular, às vezes apresentam-se poliédricas (Fig. 4). 


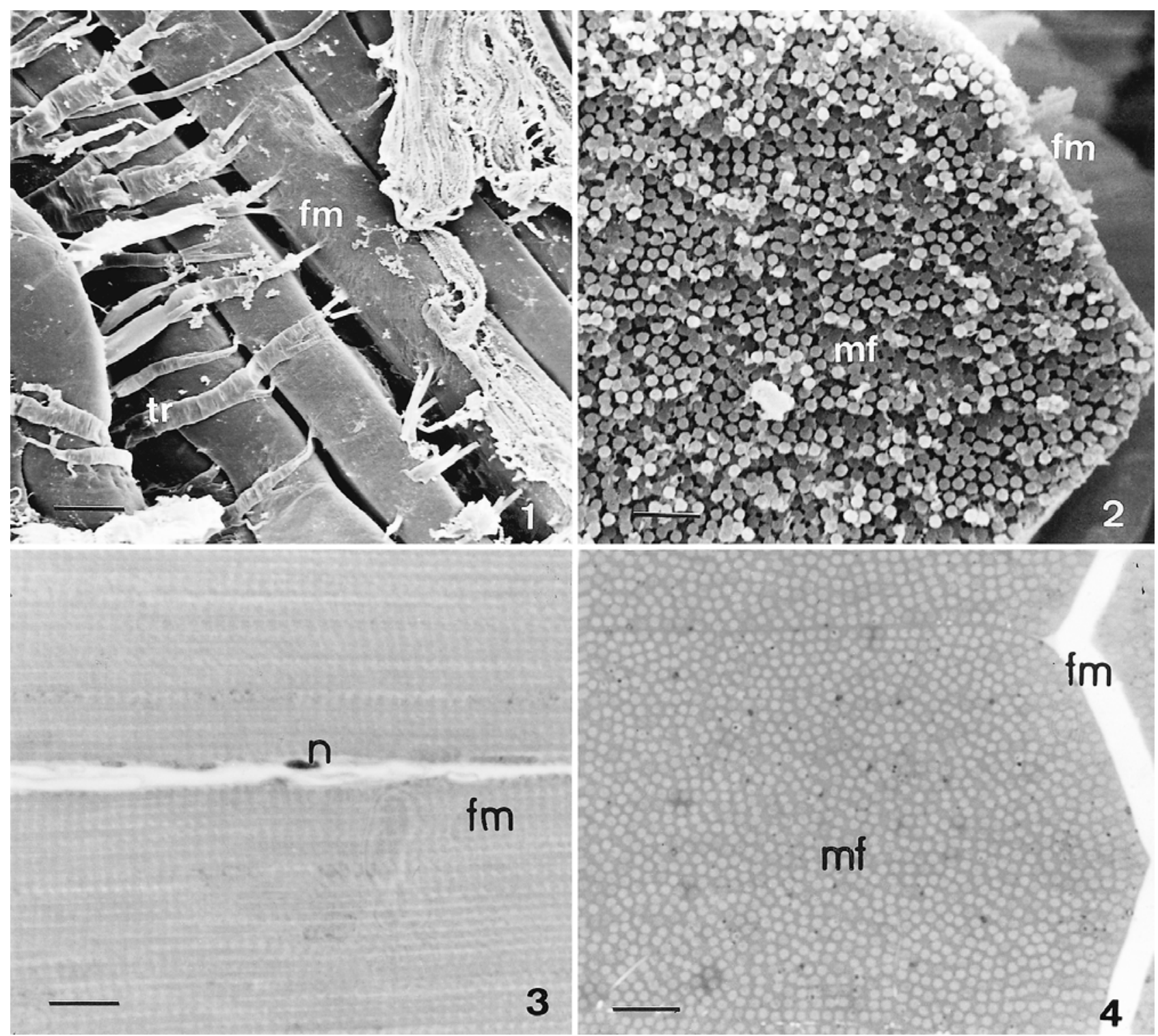

Figuras 1-4. Fibras do músculo do vôo de Scaptotrigona postica: (1) microscopia eletrônica de varredura das fibras musculares (fm) em vista longitudinal, vendo-se as traquéias (tr) que fazem sua aeração e mantém as fibras unidas; (2) microscopia eletrônica de varredura de fratura transversal de uma fibra muscular, mostrando as miofibrilas ( $\mathrm{mf}$ ); (3) microscopia óptica mostrando a estriação das miofibrilas (mf) que constituem as fibras musculares $(\mathrm{fm})$ e núcleos $(\mathrm{n})$ periféricos. Coloração hematoxilina e eosina; (4) microscopia óptica de corte transversal de fibras musculares ( $\mathrm{fm}$ ) evidenciando as miofibrilas ( $\mathrm{mf}$ ) constituintes da musculatura indireta do vôo. HE. Escalas das figuras: $1=350 \mu \mathrm{m}, 2=22 \mu \mathrm{m}, 3=40 \mu \mathrm{m}, 4=40 \mu \mathrm{m}$.

Os resultados mostraram que, em operárias recém-emergidas, a média dos diâmetros das fibras dos feixes dorso-ventrais foi de $185 \mu \mathrm{m}$, nas nutridoras foi de $213 \mu \mathrm{m}$ e de $202 \mu \mathrm{m}$ nas campeiras. O teste de "Tukey" mostrou que estes diâmetros são significativamente diferentes ao nível de 5\% (Tab. I). Ultra-estrutura

Os resultados mostraram que, nas operárias recém-
Tabela I. Diâmetros das fibras musculares do músculo dorso-ventral do vôo de Scaptotrigona postica.

\begin{tabular}{lcc}
\hline \multicolumn{1}{c}{ Operárias } & Média do diâmetro $(\mu \mathrm{m})$ & Teste de Tukey* \\
\hline Recém-emergida & 185 & $\mathrm{~A}$ \\
Nutridora & 213 & $\mathrm{~B}$ \\
Campeira & 202 & $\mathrm{C}$ \\
\hline
\end{tabular}

$\left.{ }^{*}\right)$ Letras diferentes indicam diferenças significativas ao nível de 5\%.

Revista Brasileira de Zoologia 21 (2): 379-384, junho 2004 

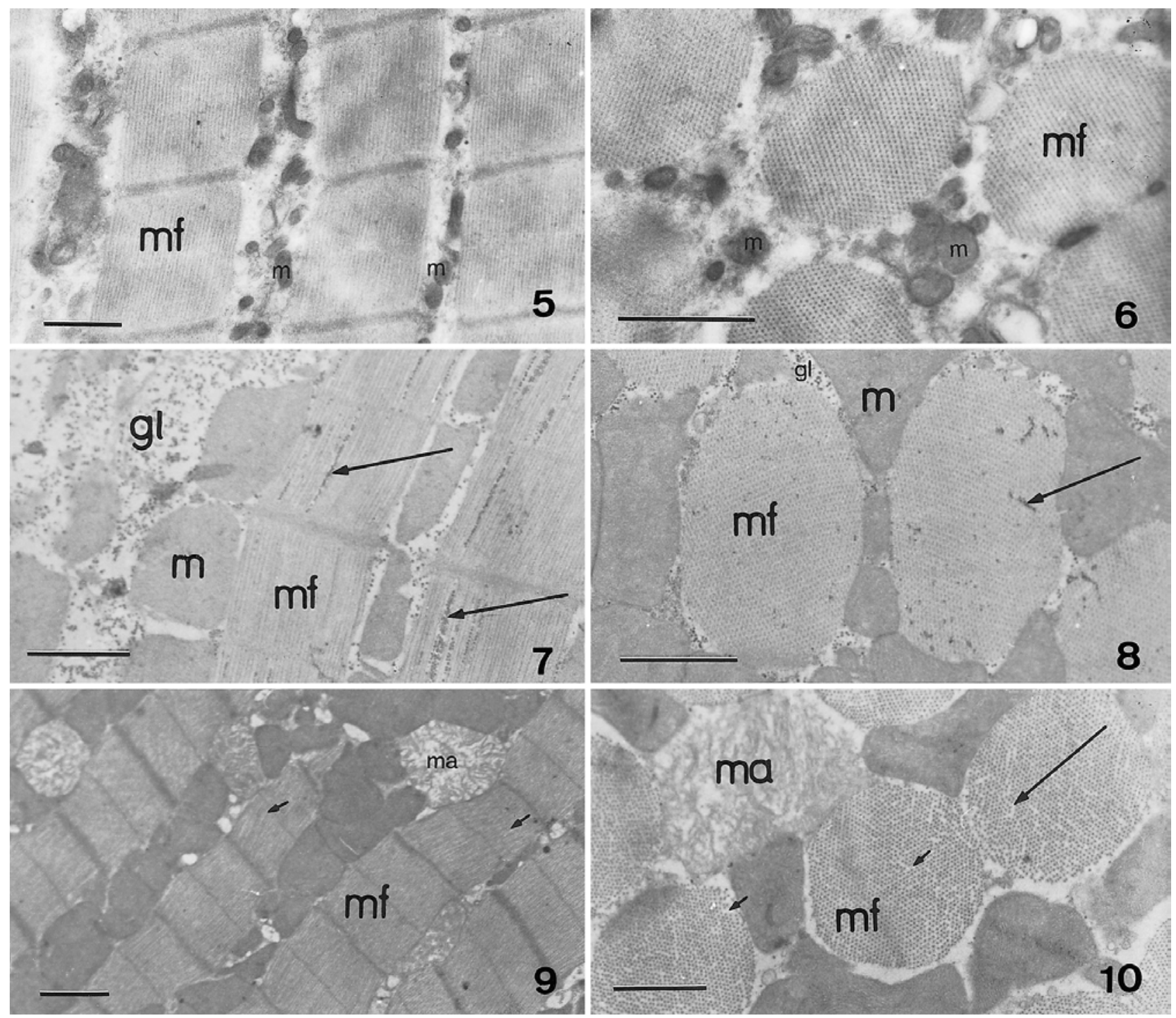

Figuras 5-10. Microscopia eletrônica da transmissão. da musculatura do vôo de operária de Scaptotrigona postica: (5) corte longitudinal e (6) corte transversal do músculo de operária recém-emergida, notar as mitocôndrias $(\mathrm{m})$ pequenas distribuídas entre as miofibrilas (mf); (7) corte longitudinal e (8) corte ligeiramente oblíquo de operária nutridora, notar o grande tamanho das mitocôndrias ( $\mathrm{m}$ ) entre as miofibrilas (mf) e grânulos de glicogênio ( $\mathrm{gl}$ ) no sarcoplasma e entre os miofilamentos (setas); (9) corte longitudinal e (10) corte transversal de operária campeira, notar as irregularidades da superfície das miofibrilas ( $\mathrm{mf}$ ) no corte longitudinal e falhas nos miofilamentos no corte transversal (setas), notar também a presença de mitocôndrias alteradas (ma) e total ausência de glicogênio. Escalas = 1 um.

emergidas, a quantidade de glicogênio é relativamente pequena, as mitocôndrias apesar de numerosas são pequenas (Figs 5 e 6) e os núcleos apresentam-se grandes e com cromatina descondensada. Nas operárias nutridoras, observa-se um grande aumento na quantidade de glicogênio distribuído no sarcoplasma e entre os miofilamentos principalmente da banda A. As mitocôndrias, apresentam-se volumosas, com muitas cristas, matriz reduzida e eletron densa (Figs 7 e 8). Os núcleos são menores e contem nucléolos bem estruturados. Nas campeiras, a quantidade de glicogênio diminuiu e algumas mitocôndrias encontram-se em degeneração. As miofibrilas apresentam falhas de miofilamentos (Figs 9 e 10) e os núcleos são pequenos e com grandes massas de cromatina condensada.

\section{DISCUSSÃO E CONCLUSÕES}

Os resultados apresentados estão de acordo com o esperado, tendo em vista o comportamento das operárias.

Os trabalhos realizados pelas operárias na colônia obe-

Revista Brasileira de Zoologia 21 (2): 379-384, junho 2004 
decem a uma determinada seqüência, de acordo com a idade do indivíduo e com as necessidades da colônia. Como em $A$. mellifera, também nos Meliponíneos as operárias constituem a casta que realiza a quase totalidade dos trabalhos de construção, aprovisionamento da colônia e cuidado com a cria (NoQUEIRA-NETO 1977).

Hebling et al. (1964), estudando operárias de Scaptotrigona xanthotricha Moure, 1945, verificaram uma seqüência de trabalhos executados por estes indivíduos que posteriormente foi também confirmada por SIMÕES \& BEGO (1979) para operárias de $S$. postica. As diferenças entre estas espécies referem-se apenas à idade em que as atividades são desenvolvidas.

SiMÕes \& BEgo (1979) dividiram os trabalhos executados pelas operárias de $S$. postica em seis grupos de atividades: a) trabalho com cera (construção das lamelas dos invólucros da área de cria do ninho, dos potes para pólen e mel, vedação de frestas e raspagem da cera das células de cria contendo pupas); b) trabalho com cria (construção, aprovisionamento e operculação das células, inserção nas células durante o aprovisionamento, oviposição e corte à rainha); c) lixeira; d) receptoras de néctar (trabalhos com resina e desidratação); e) guarda; f) campeira. As tarefas a, b, c, e d são realizadas no interior da colônia, sem necessidade de vôo. A tarefa de guarda (e) requer vôos ocasionais e constitui uma transição para campeira, tarefa esta que requer vôos intensivos.

Os presentes resultados mostram que as operárias recémemergidas (0-5 dias) têm as fibras da musculatura do vôo com mitocôndrias pequenas e pouco glicogênio disponível, portanto, estão ainda imaturas para o vôo e de acordo com a tarefa executada pelas operárias nesta idade (trabalho com cera).

Operárias nutridoras (6-45 dias) já executam maior variedade de funções. Elas desenvolvem trabalhos com cera, trabalhos na cria, lixeira, recepção e desidratação de néctar e por fim, trabalho de guarda. Os indivíduos que exercem o trabalho de guarda se incluem na faixa etária que vai de 31 a 40 dias e são em número reduzido. Para execução de tais funções necessitam de musculatura bem desenvolvida, com boa oxigenação, justificando a observação de mitocôndrias numerosas e volumosas e muita reserva energética disponível, representada pela abundância de glicogênio encontrada na musculatura das operárias nutridoras. $\mathrm{O}$ fato de serem abelhas mais jovens que as operárias campeiras, e exercerem um maior número de atividades no interior da colônia, justifica o fato de apresentarem uma musculatura melhor desenvolvida.

As operárias campeiras (30-60 dias) exercem trabalhos externos à colônia como obtenção de néctar, pólen e resina, portanto, são os indivíduos que mais utilizam a musculatura do vôo. No entanto, os presentes resultados mostram que as fibras musculares já apresentam sinais de regressão, sendo menos desenvolvidas que as das operárias nutridoras. Poderse-ia esperar que o maior desenvolvimento da musculatura do vôo ocorresse justamente na campeira em que esta é mais usada. No entanto, o maior uso causa também maior desgaste, e devido a estas operárias estarem já na etapa final de sua vida, este desgaste não é reposto na mesma escala, resultando em envelhecimento celular.

Em conclusão, pode ser afirmado que os resultados obtidos confirmam que um amadurecimento fisiológico é necessário para que as operárias possam executar as diferentes tarefas a seu encargo na colônia. No caso da musculatura do vôo, esse amadurecimento se completa na fase de nutridora, antes do início das tarefas fora do ninho. O processo de envelhecimento celular caracterizado por falhas nos miofilamentos, por mitocôndrias em processos degenerativos, e por pouco glicogênio disponível e pelos núcleos menores com cromatina condensada, observados nas operárias campeiras parece não afetar sua capacidade de vôo e deve representar a decrepitude geral do organismo em indivíduos que se encontram na fase final de seu ciclo vital.

\section{AGRADECIMENTOS}

Ao Dr. Fábio Abdalla pela ajuda na obtenção dos dados estatísticos, ao CNPq pela concessão da bolsa durante a execução deste trabalho, e a FAPESP por auxílio para aquisição de material de pesquisa.

\section{REFERÊNCIAS BIBLIOGRAFIAS}

Chapman, R.F. 1998. The insect structure and function. Cambridge, The English Universities Press, $2^{\text {nd }}$ ed., 798p.

Cruz-landim, C. 1970. Electron Microscope Observations on the Structure of the muscle insertions in: Melipona quadrifasciata anthidioides Lep. (Hymenoptera, Apidae). Revista Brasileira de Biologia, Rio de Janeiro, 30 (4): 531-537.

Cruz-landim, C. \& S.E.E. Giometti. 1990. Histólise dos músculos torácicos larvais durante a metamorfose e miogênese dos músculos do vôo em Melipona quadrifasciata anthidioides Lep. (Hymenoptera, Apidae, Meliponinae). Revista Brasileira de Biologia, Rio de Janeiro, 50 (4): 983-1002.

DALY, H.V. 1969. Skeleto-muscular morphogenesis of the thorax and wings of the honeybee Apis mellifera (Hymenoptera, Apidae). University of California Publications in Entomology, Los Angeles, 39: 1-77.

Hebling, N.J.; W.E. Kerr \& F.S. Kerr. 1964. Divisão de trabalho entre operárias de Trigona (Scaptotrigona) xanthotricha Moure. Papéis Avulsos de Zoologia, São Paulo, 16 (15): 115-127.

Nogueira-Neto, P. 1997. Vida e Criação de Abelhas Indígenas Sem Ferrão. São Paulo, Chácaras e Quintais Ed., 446p.

Pringle, J.W.S. 1949. The excitation and contraction of the flight muscles of insects. Journal of Physiology, Cambridge, 108: 226-232.

. 1957. Insect Flight. Cambridge, Cambridge University Press, 132p.

. 1965. Locomotion: flight, p. 283-329. In: M. Rockstein (Ed.). Physiology of insecta. New York, Academic Press, vol. 2, 381p.

Revista Brasileira de Zoologia 21 (2): 379-384, junho 2004 
Simões, D. \& L.R. Bego. 1979. Estudo da regulação social em Nannotrigona (Scaptotrigona) postica Latreille, em duas colônias (normal e com rainhas virgens), com especial referência ao polietismo etário (Hym., Apidae, Meliponinae). Boletim do Museu Nacional, Nova Série Zoologia, São Paulo, 4: 89-98.

SмITH, D.S. 1984. Structure of insect muscle, p. 111-146. In: C.R. KING \& H. AKAI (Eds). Insect ultrastructure. London, Plenum

Recebido em 01.X.2003; aceito em 07.VI.2004.
Press, vol. 2, IV+650p.

SMYth JR., T. 1985. Muscle systems, p. 227-252. In: M.S. Blum (Ed.). Fundamentals of insect physiology. Philadelphia, Wiley-Interscience Publication, 616p.

SNODGRASS, R.E. 1956. Anatomy of the honey bee. Ithaca, Comstock Publishing Associate, 334p.

Wigglesworth, V.B. 1974. Insect Physiology. London, Chapman and Hall, $7^{\text {th }}$ ed., 434p.

Revista Brasileira de Zoologia 21 (2): 379-384, junho 2004 